\title{
ROTEIRO SENTIMENTAL E PITORESCO DE TERESINA, UMA INTERPRETAÇÃO SIMBÓLICA
}

\section{Pablo Rodrigo Silva Martins ${ }^{1}$}

RESUMO: A Semiótica se apresenta como uma ciência caracterizada pela multiplicidade de abordagens e objetos de estudo que vão desde a arquitetura, repleta de textos não verbais, ao texto literário. A semiose deste é permeada pela atuação de ícones, índices e símbolos. Nesse sentido, texto, para a semiótica, é um complexo de significação que aponta os elementos que indicam o desenvolvimento de sua leitura, nas quais esses signos recebem relevância de modo nem sempre análogo, pois num texto literário pode haver a predominância do símbolo em detrimento dos outros elementos da composição triádica já citada, ou o contrário: o símbolo pode ser preterido em relação aos outros elementos. Assim, objetiva-se, neste escrito, analisar a obra Roteiro Sentimental e Pitoresco de Teresina, de Hildemburgo Dobal, atestando o momento de transformação pelo qual a cidade de Teresina passava no ano de centenário da capital piauiense. Para tanto, utilizar-se-á os conceitos de símbolo e significação, asseverados por Charles S. Peirce; e também a ideia de Interpretação, defendida por Humberto Eco.

PALAVRAS-CHAVE: Literatura, Semiótica, H. Dobal.

ABSTRACT: Semiotics presents itself as a science characterized by the multiplicity of approaches and objects of study ranging from architecture, full of nonverbal texts, to the literary text. The semiosis of this is permeated by the actuation of icons, indexes and symbols. In this sense, text, for semiotics, is a complex of signification that points out the elements that indicate the development of its reading, in which these signs receive relevance in a way that is not always analogous, since in a literary text there may be a predominance of the symbol in detriment of the other elements of the triadic composition already mentioned, or the opposite: the symbol can be deprecated in relation to the other elements. Thus, the purpose of this paper is to analyze Teresina's Sentimental and Picturesque Roadmap, by Hildemburgo Dobal, attesting to the moment of transformation through which the city of Teresina passed in the centennial year of the Piauís capital. To do so, we will use the concepts of symbol and signification, as asserted by Charles S. Peirce; and also the idea of interpretation, defended by Humberto Eco.

\footnotetext{
${ }^{1}$ Professor EBTT, no IFPI, campus Oeiras. Ministra as disciplinas de Português, no Ensino Básico e Redação Técnica e Atividades Linguísticas, nos cursos de Gestão Ambiental e Matemática, respectivamente. Como pesquisador, atua na relação entre Literatura, Cidade e Memória, bem como na relação Literatura, Memória e Identidade. Email: pablo.martins@ifpi.edu.br
} 
KEYWORDS: Literature, Semiotics, H. Dobal.

A segunda tricotomia Peirceana, ícone, índice e símbolo, diz respeito às relações semânticas entre o signo e seu objeto. Dessa forma, o ícone, segundo Peirce (1977, p. 64), "é um Representamen cuja Qualidade Representativa é uma sua Primeiridade como Primeiro. Ou seja, a qualidade que ele tem qua coisa o torna apto a ser um representâmen." Isto é, mantém relação direta com seu objeto, como uma fotografia legendada, que pode ser um substituto daquilo fotografado. Por isso, segundo Peirce (1977), pode-se afirmar que uma das formas de comunicar uma ideia direta perpassa por um ícone, assim como as formas indiretas de comunicação devem partir dele.

O índice é um signo que mantém conexão real com seu objeto, resultado da existência deste. Peirce (1977, p.69) afirma que "Alguns índices são instruções mais ou menos detalhadas daquilo que o ouvinte precisa fazer a fim

de pôr-se em conexão experiencial direta ou de outro tipo com a coisa significada". Dessa forma, a estrela polar constitui-se como um índice que localiza o hemisfério Norte, isto é, os índices são rastros daquilo que o ouvinte/leitor precisa seguir para conectar-se com a coisa significada.

O símbolo é um signo que se associa a seu objeto por força de convenções ou hábitos. Sendo lei, o símbolo "é um Representámen cujo caráter representativo consiste exatamente em ser uma regra que determinará seu Interpretante.” (PEIRCE, 1977, p.71). Assim, símbolo é um signo cuja significância liga-se diretamente ao fato de haver pessoas predispostas a interpretá-lo como tal. Peirce (1977) afirma que

Qualquer palavra comum, como 'dar', 'pássaro', 'casamento', é exemplo de símbolo. O símbolo é aplicável a tudo o que possa concretizar a ideia ligada à palavra: em si mesmo, não identifica essas coisas. Não nos mostra um pássaro, nem realiza, diante de nossos olhos, uma doação ou um casamento, mas supõe que somos capazes de imaginar essas coisas, e a elas associar a palavra. (p. 73.)

O símbolo somente se constitui a partir do momento em que há uma associação convencional entre o objeto e o signo, pois este quando suas qualidades apenas se assemelham àquele caracteriza-se como ícone. Quando está fisicamente ligado a seu objeto, sem a interferência cognitiva, configura-se como um índice. Agora, o símbolo surge quando o signo se liga ao objeto por intermédio de uma ideia, sem o qual essa ideia não existiria.

A representação simbólica de uma obra literária se sobressairá a partir do momento em que os signos utilizados pelo autor suscitarem sentidos convencionais. Assim, as associações entre o signo utilizado no texto literário e o objeto representado devem fundamentar-se em hábitos socialmente concretizados. A partir dessa concepção, A obra "Roteiro Sentimental e 
Pitoresco de Teresina", de H. Dobal pode ser analisada pelo viés simbólico, visto que os signos utilizados pelo autor associam-se a sentidos socialmente estabelecidos.

Deve-se levar em consideração ainda, no processo analítico da obra literária, o efeito produzido pelo signo sobre o intérprete, resultando em uma significação, que nas palavras de Coelho Netto (1990, p. 72), "é o resultado interpretativo a que todo e qualquer intérprete está destinado a chegar, se o signo receber a suficiente consideração". Nesse sentido, o texto é o responsável pelas possibilidades interpretativas existentes neles. Diferentemente das concepções que atribuem ao autor e ao leitor os únicos guardiões pela interpretação do texto, há segundo Eco (1993, p.28) uma intenção do texto. "As palavras trazidas pelo autor são um conjunto um tanto embaraçoso de evidências materiais que o leitor não pode deixar passar em silêncio, nem em barulho", a fim de evitar superinterpretações.

Lançando um olhar a sua cidade natal, H. Dobal traveste-se de flâneur e percorre alguns pontos de Teresina, observando-os e saudosamente constata que as mudanças ocorrem de forma irreversível. Ao retratar, em seu Roteiro, a Teresina que se transfigura, o narrador mantém contato com os espaços da cidade carregados de memórias. Espaços estes responsáveis por escrever a própria história da cidade, pois o espaço urbano pode ser comparado a um texto verbal. Neste, as palavras são selecionadas, combinadas, formando frases que resultam em textos significantes; já naquele, elementos da cidade são organizados de modo que resultam num lugar repleto de significado.

Levando em consideração os conceitos de símbolo, significação e interpretação, analisarse-ão alguns fragmentos da obra literária citada acima. No capítulo intitulado As ruas e os bairros, o narrador afirma que:

As ruas nasceram retas, mas não muito largas. Retas porque a isto se prestava muito bem a situação do lugar. Largas, por quê? Quem poderia prever naquele tempo que um dia haveria necessidade de espaço para automóveis e muita gente? (DOBAL, 1999, p.13)

Pode-se perceber que o narrador posiciona-se num dado tempo no qual pode confrontar o passado com o presente, a partir do uso da construção sígnica naquele tempo, utilizado para se referir a um tempo já transcorrido, tendo como referência o presente. Ao indagar os motivos pelos quais as ruas nasceram largas, o narrador utiliza por quê, um signo cristalizado socialmente relacionado à busca de respostas, que significa que a cidade passa por uma transformação que não se vislumbrava num dado passado. Para reforçar essa intepretação, há no texto a presença da locução verbal poderia prever, deixando rastros: realmente essa transformação era inesperada, mas que ocorria contemporânea ao autor. 
Em outra passagem pertencente ao mesmo capítulo, o narrador observa a cidade e percebe que

A cidade tem o seu progresso, as ruas a sua agitação mas ainda permitem o trânsito sem sustos. À noite ficam mais calmas, de uma tranquilidade interrompida apenas pelos grupos que conversam, sentados em cadeiras, nas calçadas. [...] Depois das nove quando desaparecem os últimos rumores e elas ficam entregues ao luar verlaineano, às vezes, alguns notívagos e românticos improvisam serenatas, o langor dos violões sob as janelas insensíveis das amadas adormecidas (DOBAL, 1999, p. 14)

Percebe-se que o autor presencia o momento em que a cidade sofre alterações em suas estruturas. $\mathrm{O}$ signo $A$ cidade tem o sen progresso, indicativo, significa realmente que a cidade se moderniza, progride, é agitada. Ratificando o momento de transição, a expressão mas ainda permitem o trânsito sem sustos solidifica-se como sequência textual que permite que se conclua que apesar desse progresso, ainda resistem comportamentos que prendem a cidade ao provincianismo.

A construção sígnica "depois das nove quando desaparecem os últimos rumores e elas ficam entregues ao luar" permite ao intérprete que perceba a cidade com um caráter interiorano, visto que nessas cidades as pessoas se recolhem cedo, o reflexo lunar encanta as pessoas e a prática da serenata é utilizada nas investidas amorosas, enquanto que nos grandes centros urbanos, que não dormem, a poluição atrapalha o espetáculo da lua e os amantes se utilizam de outros artifícios em suas relações amorosas.

A mudança de comportamento dos consumidores do espaço urbano deve ser um termômetro para as transformações neste. Ferrara (1988, p.40) assevera que "a cidade é mensagem à procura de significado que se atualiza em uso", e esse uso deve incorporar os novos hábitos e possibilidades. Essa questão é visualizada na obra, quando o narrador diz que

\footnotetext{
Na praça Deodoro, que tem ainda o nome de Parque da Bandeira, nasceu a cidade. [...] Viveu abandonada muito tempo. Depois lembraram-se de transformá-la em algo melhor. Foi toda cercada de sebes de fícus, cuidada, limpa e se tornou viveiro de pássaros e de alguns animais. Havia bandos de canários, rolinhas, e dos animais, [...]. Mas então surgiu um problema difícil. Através da praça passava o povo que ia para o mercado e que, tendo o seu caminho barrado pelas cercas, não se conformava em fazer a volta. [...] Mudaram os tempos. Afinal as praças são do povo. As cercas foram retiradas, os animais fugiram. O macaco tomou o seu destino, a anta entregou-se ao rio. A praça voltou ao abandono. (DOBAL, 2007, p. 19)
}

Reflexo da mudança de postura dos habitantes, a praça, que genuinamente serve para o encontro, para as conversas e lazer, passou a servir apenas como um percurso mais rápido entre a origem e o destino das pessoas, por isso, o narrador utiliza a construção Viveu abandonada muito tempo, resultado do olhar automatizado das pessoas lançado à praça. Olhar automatizado característico das cidades metropolitanas ou em processo de metropolização, onde o tempo exíguo faz com que as relações se desestruturem; nesse sentido, o povo não se conformava em fazer a volta. Como reflexo das mudanças dos citadinos, a praça voltou ao abandono. O verbo voltar, no 
pretérito, confirma que após um abandono inicial, cessado momentaneamente pela vitalidade dos animais, retornou ao estado de outrora.

Em outro olhar lançado à cidade pelo narrador, materializado no texto literário, pode-se visualizar o momento de transição urbana. Ainda sobre a relação entre as pessoas e as praças, o narrador observa que:

A praça João Luís (aqui há este costume de tratar as praças com certa familiaridade) é das crianças, dos namorados e de árvores que têm um breve outono, quando se desfolham antes da floração. Nesta praça está situado o modesto arranha-céu da cidade, o prédio de oito andares do IAPC e nela existiu outrora um playgroud. Hoje os balanços e as gangorras desapareceram, mas as crianças ainda brincam e jogam sob o olhar complacente das amas ou dos irmãos maiores e dão à pracinha descuidada e triste um ligeiro ar de vida infantil que não interrompe a solidão dos namorados. (DOBAL, 2007, p. 20)

Em referência ao prédio, situado na praça, há o uso do adjetivo modesto que carrega em si uma carga semântica contida, quando o assunto é arranha-céu. Pode-se perceber que o prédio citado é o único da cidade, pelo uso do artigo definido $a$, em oposição aos centros urbanos já desenvolvidos. Ao usar o signo hoje, o narrador novamente se põe numa posição no presente, mas sem retirar os olhos do passado, presenciando esse processo. E a partir das marcas encontradas na cidade, o narrador, através da sensibilidade do flâneur, se torna uma testemunha ocular das mutações citadinas.

Os significados que emanam da cidade, refletidos num texto literário, são diversos, visto que ao passar pelo olhar subjetivo do indivíduo, a cidade ganha significação diferente, ou seja, em uma única cidade, há a presença de várias cidades, como assevera Calvino (1999). Todavia, a disposição arquitetônica da cidade contribui para que a memória citadina seja suscitada pelas gerações vindouras. Nesse sentido, Santos (1998, p. 22) assegura que "Ao longo da história, a arquitetura tem sido, também, um testemunho através do qual gerações passadas informam às seguintes quem eram, como viveram, que sociedade construíram", e assim, a cidade transmite suas memórias.

Assim, pode-se perceber que a semiose do texto de H. Dobal, à luz de interpretações simbólicas, reflete um momento de transformação pelo qual a cidade de Teresina passava. O narrador, ao modo flâneur, observa esse momento, como se dele não fizesse parte, confrontando o antes e o agora e vislumbrando um devir inevitável. Os signos utilizados na tessitura do texto agem cognoscitivamente no intérprete, fazendo com que este não se distanciasse das evidências materiais expressas, ou seja, é possível interpretar o texto a partir do que ele deixa desvelar. 


\section{REFERÊNCIAS}

CALVINO, Ítalo. As cidades invisivivis. São Paulo: Companhia das Letras, 1990.

DOBAL, Hidenburgo. Roteiro Sentimental e Pitoresco de Teresina: Obra completa II: Prosa. 2 ed. Teresina: Plug, 2007.

ECO, Humberto. Interpretação e superinterpretação. Trad. MF. São Paulo: Martins Fontes, 1993.

FERRARA, Lucrécia d'Aléssio. Ver a cidade: cidade, imagem, leitura. São Paulo: Nobel, 1988.

NETTO, J. Teixeira Coelho. Semiótica, Informação e Comunicação. Coleção debates: Semiótica. São Paulo - SP: Editora Perspectiva, 1990.

PEIRCE, Charles Sanders. Semiótica. São Paulo: Editora Perspectiva, 1977.

SANTOS, Lúcia Leitão. Os movimentos desejantes da cidade: uma investigação sobre os processos inconscientes na arquitetura da cidade. Recife: Fundação de Cultura do Recife, 1998. 